\title{
Voices from the Post-Katrina Ninth Ward: An Examination of Social Justice, Privilege, and Personal Growth
}

\author{
Paul B. Perrin \\ Angelica Brozyna \\ Andrea B. Berlick \\ Frederic F. Desmond \\ Huan J. Ye
}

University of Florida

Elza Boycheva

State University of New York, Binghamton

\begin{abstract}
We-five graduate-student counselors and one professor-provided social support to AfricanAmerican residents in New Orleans' post-Katrina Ninth Ward. We describe residents' narratives, our reactions to our own privileges made salient, our personal growth, and post-Katrina social injustice. We then suggest ways for individuals to contribute to disaster relief/social justice.
\end{abstract}

Keywords: Hurricane Katrina, social justice, disaster relief, privilege

To get to the Lower Ninth Ward from central New Orleans, you drive on North Claiborne Avenue over a short, steep bridge. Its metal grates obscure your view, and it is not until you reach the top of the bridge that the Lower Ninth Ward appears in its entirety. Even six months after Hurricane Katrina, the scene is so shocking that numbness and disbelief overwhelm you as you try to take in the faint echo of the neighborhood. Debris scattered across concrete foundations mark where homes once stood, and smashed cars, appliances, boats, and furniture line the horizon. Before Hurricane Katrina, the Lower Ninth Ward's population was $98.3 \%$ African-American (Greater New Orleans Community Data Center, 2007), and many of these 
Journal for Social Action in Counseling and Psychology

Volume 1, Number 2, Spring 2008

residents were without the means to evacuate before the storm. The Lower Ninth Ward is adjacent to one of the levee breaks, and estimates suggest that a 20-foot wall of water swept through the neighborhood (Warner \& Scott, 2005). Many of the homes next to the levee are too damaged to be rebuilt, but a half mile or so away from the levee, some residents have returned to salvage what memories are left, and in some cases, to start rebuilding resiliently from the foundation up.

With the aim of providing social support to residents returning to their homes in the Ninth Ward a team of five counseling psychology graduate students and one professor spent seven days there in March 2006. This article presents our experiences and has three overarching aims: (a) to amplify some of the voices of the residents in New Orleans' Ninth Ward, (b) to discuss our personal reactions to what we saw and experienced, and (c) to suggest possible ways in which counselors, psychologists, and graduate students can contribute to disaster relief efforts motivated by social justice.

\section{Social Injustice in Katrina's Wake?}

Several statistics document the ethnically and economically disproportionate destruction of property and lives in and around post-Katrina New Orleans. Before the hurricane, the median household income in Orleans Parish was $\$ 27,133$, compared to the U.S. national average of $\$ 41,944$ (U.S. Census Bureau, 2004). Twenty-seven percent of households did not own an automobile, and $67.9 \%$ of the population was African-American (U.S. Census Bureau, 2000). New Orleans mayor Ray Nagin has suggested that the federal government's slow response was due to prejudice toward New Orleans' large population of ethnic minorities and individuals in poverty. In a 2006 interview, he said that Hurricane Katrina "exposed the soft underbelly of America as it relates to dealing with race and class.... And I, to this day, believe that if that would have happened in Orange County, California, if that would have happened in South Beach, Miami, it would have been a different response" (Associated Press, 2007). According to many, Katrina's aftermath amplified New Orleans' racial and economic inequalities.

Most psychological distress models posit that vulnerable populations with few economic and social resources are particularly prone to problems with coping, and disasters intensify social inequalities among populations who already experience chronic adversity (Richmond, 1993). For example, African-Americans are more likely than European-Americans to develop post-traumatic stress disorder (PTSD), especially after a natural disaster (Pole, Best, Metzler, \& Marmer, 2005). An ethnic minority group with a long history of discrimination will understandably face coping difficulties different from those of the majority population. Because of the social injustices in Katrina's wake-whether psychological, social, or physical-we decided to initiate a project that would tap the clinical skills we had been developing in our counseling program and target one of the New Orleans neighborhoods that had been hit hardest.

\section{The Relief Project}

In January 2006, we proposed a New Orleans relief effort to our psychology faculty, asking for financial donations and more in-depth disaster training than what we had already been receiving in our program. Our goal was to join an active New Orleans relief organization and provide "social support" to residents. Though we were counseling students, we made it very clear that we did not intend to perform psychotherapy or to develop short-term and potentially 
Journal for Social Action in Counseling and Psychology

Volume 1, Number 2, Spring 2008

problematic therapeutic relationships. Instead, our vision of social support involved using the active listening skills we were developing in our counseling program to talk with residentsrespecting and appreciating their experiences. Put simply, we wanted to show residents that though we were not personally affected by the hurricane, and though we were of different socio-economic statuses, education levels, and ethnicities, we cared about them. Their struggle was not invisible to us. We felt that we might be better trained than the average volunteer in showing residents this interpersonal compassion.

Our psychology faculty gave private donations that quickly exceeded our cost estimates, and four psychologists in our area provided us with approximately ten hours of crash-course training on disaster relief, crisis intervention, and multicultural sensitivity. One of these psychologists had grown up in New Orleans; the second was the director of a local crisis center; the third was a nationally respected researcher on multicultural sensitivity in health care; and the fourth was a national consultant in crisis response, and had worked with the federal government immediately after September 11 . The most notable parts of our training included a dialogue with a panel of African-American graduate students about coping with trauma, a seminar on typical trauma reactions, and a dialogue with the New Orleans psychologist about Ninth Ward culture. Then, in close contact with two Gulf-Coast psychologists, we formulated a project to work with Common Ground Collective (CGC), a relief organization based in New Orleans.

One of CGC's central objectives is to provide post-Katrina assistance to and advocacy for African-Americans in the Ninth Ward. Sakura Kone, media coordinator for CGC, sums up the organization's focus: "We've got a revolution on our hands; one side includes the powerful, political corporations, and the other side consists of poor Blacks" (Get on the bus, 2006). CGC provides the Ninth Ward with free health clinics, women's shelters, food distribution centers, tool lending services, house gutting, and weekly community meetings to bring residents together. Melik Rahim, founder of CGC, said in an interview regarding the types of volunteers he was looking for, "[I] didn't make a call just to those who believe in bringing relief-I made a call to those who stood for peace and justice to come down" (Interview with Melik Rahim, 2006). In joining CGC, we felt that we had the chance not only to help rebuild New Orleans, but also to face some of the injustices that persist in the city after Katrina.

During our spring break, the six of us drove to New Orleans. At the Ninth Ward CGC relief site, we slept in a large tent with 20 of the hundreds of other CGC volunteers. The walls of our communal showers and toilets were plastic tarps, and cooks prepared meals for us and the hundreds of volunteers who were there to gut homes. On our first day, we performed a number of odd jobs such as repairing plumbing, moving furniture to a women's shelter with our van, preparing food, as well as stocking and dispensing supplies at the central CGC distribution center. On the second day, after getting a feel for the way CGC operated, we worked with the volunteer coordinator to create a community outreach structure. We felt that establishing this role for ourselves would allow us to apply our counseling training to attract more residents to CGC.

\section{Working with Residents}

As community outreach representatives for CGC, we drove through Ninth Ward neighborhoods handing out water, food, and resource information to residents rebuilding their homes. We approached residents in groups of two, identified ourselves as CGC volunteers, and asked them 
Journal for Social Action in Counseling and Psychology

Volume 1, Number 2, Spring 2008

open-ended questions such as, "How are you doing?" "Is there anything we can help you with?" or "What problems are you facing now?" With little prompting from us, most residents took a break from working and told us about their lives and experiences. Many were working alone and seemed to welcome sharing their stories with us. Often these conversations lasted over an hour because residents walked us around their homes and explained the challenges they were facing. To residents displaying noticeably problematic adjustment issues, we gave pamphlets describing the nature of typical psychological trauma responses and containing contact numbers where residents could obtain free professional mental health support.

The following sections of this article are derived from extensive field notes that each of us wrote independently at the end of every day. These notes include descriptions of the residents we had spoken with, summaries of the stories they had told us, and accounts of our personal reactions to interacting with residents. After we returned from New Orleans, we began to work on this article by meeting to identify common, salient themes among our field notes. We noticed five major themes, often overlapping, in our field-note accounts the Ninth Ward residents' stories: (1) trauma reactions, (2) social injustice, (3) resilience, (4) hope, and (5) a sense of community. The following five sections present examples of each of these themes and describe our reactions to the residents who voiced them.

Rappaport (2000) suggests that "giving voice" to oppressed groups includes helping communities create shared narratives about their experiences. Similarly, Goodman et al. (2004) suggest that psychologists "must find ways to amplify the voices of community members so that others can learn about their needs, wishes, strengths and vision" (p. 803). This article is an attempt both to create a shared narrative and to bring that narrative to the counseling and psychological communities. In the interest of residents' privacy, we have changed the names and omitted potentially identifying details. The pseudonyms provide continuity throughout the article because we often mention the same resident in different thematic sections.

It is important to note that this article is not a scientific study, but rather a subjective description of our experiences interacting with residents of the Ninth Ward. Addressing psychologists working toward change in communities, Goodman et al. (2004) suggest that "rather than pretend objectivity, they should simply recognize each of the selves that emerge over the course of the work" (p. 800). Following this advice, we are embracing the subjectivity of our own viewpoints, and this article moves back and forth between residents' experiences and our own. Our relief effort was not an intervention study, so the only outcome we know for certain of our work rests not in the psychological well-being of the residents we engaged, but rather in our own personal growth and development as young psychologists trying to work toward our ever-evolving conceptions of social justice.

\section{Trauma Reactions}

Though we did not know exactly what we would find in talking with Ninth Ward residents, we knew that we would see a number of typical trauma reactions. In this regard, the crisis intervention training we had received before the trip proved vital in helping us work compassionately with residents. For example, several residents shared vivid memories of a wave of water rushing toward them from the levee breaches, their neighbors' cries for help, the silence after the cries, and, tragically, bodies floating past their rooftops. One resident, Bernie, told us of recurring nightmares about the time he had spent on his roof. Numbness, he said, 
Journal for Social Action in Counseling and Psychology

Volume 1, Number 2, Spring 2008

was his only way of coping with those memories. Bernie's neighbor Wendy had evacuated New Orleans before the flood, thinking she would return in a few days to her normal life. Instead, she returned months later to a devastated home with a feeling of isolation and "nothingness."

Though some residents exhibited blunted affect, others displayed strong emotions. Sarah said that she felt exhausted and overwhelmed, frustrated because she did not know how to begin the daunting task of rebuilding her home and former life. Many other residents felt frustrated as well, often due to the lack of progress in rebuilding their homes and community. Depression was a common reaction. Darrel described how his wife had felt defeated after Katrina leveled their home. She and many others felt that moving back to New Orleans would be too painful because of the memories of what was lost. Darrel shared his wife's reluctance, he said, because even if it were possible to rebuild, the rest of the neighborhood might never recover. That fact made him feel "alone."

Especially poignant for us was the story of Bernie, who lived in the Lower Ninth Ward, close to a breach in the levee. Bernie walked us through his devastated home, reenacting the day of the flood. He described the wall of water rolling toward him "like a doughnut" and showed us how he had slammed his front door, rushed through the hall, and pulled down the ladder to his attic. As he told his story, Bernie climbed the ladder and shook it: "This is where I was when the wave hit my house." Bernie recalled grabbing a hammer as he climbed, and he pointed to a gaping hole he had hammered through his roof to escape the rising water. He said he had sat on the roof for two days, "watching bodies float by and killing spiders." Finally, Bernie described his rescue by boat and his five-day stay in the Superdome, recounting details of the oppressive heat and stench, as well as of his actions in helping others. As he finished, we realized we were the only people to whom he had shown his house since he had returned to New Orleans. We felt especially honored that we were able to listen to him and validate his feelings.

Talking with Ninth Ward residents, we had our own reactions, some of which mirrored to a much lesser degree the trauma reactions of residents themselves. Many of us alternated between emotional numbness, intense anger, sadness, and guilt. Trying to make sense of the destruction and our reactions to it often brought surreal confusion. At times, we felt detached from reality, and memories of our own homes seemed distant. Following the advice of a faculty member, we had brought pictures of our families to provide a sense of normalcy. The pictures seemed out of place among our surroundings; even phone calls home felt odd because loved ones could not fully understand what we were experiencing. On a small scale, we began to appreciate how residents may have felt amid their devastated lives.

Many of us shared another powerful trauma reaction when for the first time we drove across the industrial canal to the Lower Ninth Ward. The sight from the top of the bridge brought simultaneously a wave of numbness and an overload of thoughts and emotions that made it hard to comprehend what we saw. One member of our group describes his response: "The scene took my breath away. I remember gasping and gripping the steering wheel as hard as I could so that I wouldn't drive off the side of the bridge." We walked through what was left of the neighborhood, and it looked like nothing we had ever seen. Concrete slabs remained where the flood had washed away homes, along with some of their occupants. Two mangled, pink tricycles with Mardi Gras beads on the handlebars rested against an overturned chain linked fence. For many of us, intense emotions would normally have accompanied this experience, but the shock produced only numbness. We could only wonder. 
Journal for Social Action in Counseling and Psychology

Volume 1, Number 2, Spring 2008

\section{Social Injustice}

In Katrina's aftermath, many residents continued to cope with a man-made disaster that had been present in New Orleans long before Hurricane Katrina blew ashore. George, a resident in the Upper Ninth Ward, spoke about the injustice that he felt many New Orleans residents were facing. He told us, "What's happening here isn't a Black thing, it's not a White thing, and it's not a political thing. This is something that affects everyone, no matter who you are. It's just that the poor are the ones hit hardest, and a lot of the poor are Black." George said he saw the situation primarily as a problem of economics. He felt that poor people were suffering the most because they were far less able than the middle-class to access government aid. Six months after the storm, George was upset that he was still waiting for a Federal Emergency Management Association (FEMA) trailer, and for help in rebuilding his home. Another resident, Glen, expressed similar frustration, saying that the government had given money to people with bank accounts very early, but that people without bank accounts had no way of accessing that aid.

Maria, too, spoke about the injustices that residents in New Orleans were facing. After her home had been destroyed, she and her family had moved into a predominantly AfricanAmerican community in Atlanta. Maria explained that she and many others forced to relocate encountered coldness and job discrimination from some permanent residents and business owners. People resented others moving in, crowding their neighborhoods, and competing for jobs that were already scarce. Maria spoke about how much she missed living in the supportive community that New Orleans had been. Tammy, a resident living in a women's shelter, had faced similar injustice after relocating. She told us that her husband was currently in Tennessee working in construction to support her and their baby. Though Tammy had applied for jobs in Tennessee, she had been unsuccessful because "No one wants to hire a refugee." Tammy told us that she had also tried to get a job in New Orleans, but unreliable public transportation made her search difficult.

For us, hearing residents' stories of injustice was often difficult. Because most residents we met did not want to leave New Orleans, we were especially surprised and angered by the relocation injustices they described. Many had lost their homes and some had lost family members, so their prolonged discrimination was a second or third tragedy. Some of the middle-aged residents we met in the Ninth Ward had saved for years to purchase their homes, and some families had lived in the same home for generations. Glen, for example, showed us the beams in his home that his great-grandfather had framed. Lacking flood insurance, most of these families could not purchase another home.

In contrast to the Ninth Ward, the above-sea-level French Quarter was relatively unscathed by the hurricane and flood; many businesses there were open during our time in New Orleans. A number of Ninth Ward residents talked about the French Quarter and said they felt happy that the French Quarter was still functioning because it gave them a sense that New Orleans had survived and could become the soulful city it once had been. George told us he had seen Mayor Ray Nagin on television saying that he wanted to rebuild New Orleans as "a chocolate city" of 
Journal for Social Action in Counseling and Psychology

Volume 1, Number 2, Spring 2008

African-Americans. George said that this remark offended him because predominantly European-American neighborhoods like the French Quarter were as vital to the soul of New Orleans as were African-American neighborhoods like the Ninth Ward. Though many residents like George expressed pro-White sentiments to us, they may or may not have been hiding their true feelings from us because most of us were European-American.

Psychologists in our pre-trip training had warned us that Ninth Ward residents might reject us as middle-class Asians and Whites unable to identify with their predicament, or simply as intrusive outsiders. Indeed, some residents were initially wary of our intentions; but, on hearing of our purpose, most appeared to trust us with personal stories that often reflected painful thoughts and feelings. Though every resident we worked with was African-American, and none of us was, we often felt deeply connected with them. Residents seemed to be open to discussing even difficult topics like social injustice. But, of course, it would be naïve to assume that residents felt as connected or comfortable with us as we did with them-we can only rely on our own perceptions.

Though many residents made us feel comfortable by minimizing the differences between us and them, those differences were strong and constantly visible. Across multiple domains, we were persons of privilege. We were either European-American or Asian; we were all middle-class; we all either had doctorate degrees or were working toward one; and most of all, we had not been personally affected by Hurricane Katrina-we could go back at the end of our trip to our intact homes and lives. Few, or probably none, of the people with whom we interacted had these same privileges. As a result, we often feared that the differences between us would limit our abilities to connect with them. We saw the residents suffering, but the level to which we were affected by what we saw paled in comparison to what they were experiencing. In fact, we often felt helpless because we wanted to combat some of the injustices but did not know how. Despite our privileges, however, we were able to gain from residents an expanded appreciation for cultural differences and an increased comfort in interacting with people of vastly different backgrounds and life experiences.

\section{Resilience}

The interiors of most residents' homes were completely demolished in the flood. Distorted pictures in cracked frames often lay on warped wooden floors. Other familiar objects were destroyed and unsalvageable. Yet for many residents who did not return, the combined financial and emotional price of rebuilding their homes was probably higher than that of relocating to another city. However, despite these costs, many residents decided to return home. The Ninth Ward was their neighborhood-where their children and grandchildren had grown up.

We found two such women-Deborah, who was in her 50s, and her mother, Emma, who was in her 80s-using a machete and a sling blade to hack down huge weeds around their house. A plank nailed to their front door bore an official pink paper designating the house as dangerous; it appeared that no one had entered the house since the flood. When we approached and offered help, Emma showed us how to use a sling blade, Deborah handed us her machete, and we worked side by side with them for two hours as they pulled weeds. "A church group was supposed to help me gut the house," Deborah told us. "Instead of just waiting, I had to get started." So Deborah and Emma, their house uninhabitable, worked in the New Orleans heat to 
revive their "lawn." What they and other residents said they wanted was a return to the way things were. In this case, simple yard work-though perhaps futile-gave us a sense of progress, which may have been what these two women felt as well.

Frank, another resident, displayed similar resilience. Shortly after Katrina, he told us he had made several trips from Atlanta, where he was temporarily relocated, to survey damage to his home in the Ninth Ward. Unable to arrange assistance through FEMA or the City of New Orleans, he and his wife were again relocated to Alabama, many miles from New Orleans. Yet, as Frank recounted his troubles, he kept smiling and telling us, "But I'm not complaining." By the time we met Frank, he and his wife had found local housing, and he was beginning to see his efforts pay off. A power pole had been installed in front of his home, the city had declared his water safe, and he expected his trailer to arrive any day. Frank said that only his persistence had made these things happen.

Frank and many others we met demonstrated an inspiring resilience. Having lost a lot, they returned to the Ninth Ward, determined not simply to subsist, but to rebuild their property, or what remained of it, and their lives. We realized, of course, that these were New Orleans residents with both the will and the means to return. Because most of the houses in the Ninth Ward appeared untouched since the flood, it is reasonable to infer that many other residents lacked that will or the means.

\section{Hope}

Like resilience, hope was a pervasive theme in the stories we heard. When we arrived at CGC, word was spreading that after six months a young boy had been reunited with his father. CGC volunteers rejoiced at this news because it gave hope to residents still looking for loved ones. Such stories were a major source of hope for residents because as of March 2006 (when we were in New Orleans), 5,088 children had been reunited with their families (National Center for Missing and Exploited Children, 2006).

Another source of hope for residents was religious faith. One resident, Elizabeth, said her belief in God sustained her as she repaired her home. Her sister Linda seemed to strike a balance between her own faith and Katrina's devastation. "God has reasons for doing things," she told us. "If something really bad happens, something good will follow." When residents described positive aspects of their situations, they often mentioned or alluded to faith as a source of strength for rebuilding their lives. Some of the residents explicitly spoke of their beliefs; others used language that, while not explicitly religious, sounded spiritual, mystical, or fatalistic. "The bad people got what they deserved," said Linda, "and the good people are left here to rebuild."

Many residents also expressed hope for the future of New Orleans. Compared with the first quarter of 2005 (and adjusted for population change) violent crime in the first quarter of 2006 had dropped 26\%; nonviolent crime had dropped 1\% (Philbin, 2006). In the Ninth Ward, many residents seemed aware of these statistics. Mary, for example, said that although the hurricane had destroyed much of New Orleans, she hoped to see the city rise again without the gangs and drugs that had plagued the streets. She also saw rebuilding as an opportunity to revive the soul of New Orleans in strong communities based on "common love and support." Darrel expressed a similar hope because, as he said, everyone he knew who had returned was a good person. Hoping for a stronger, more tightly-knit, and safer community, he believed New Orleans 
Journal for Social Action in Counseling and Psychology

Volume 1, Number 2, Spring 2008

now had the opportunity to rebuild without what he called "the riff-raff." Unfortunately, this decrease in crime did not continue for long, and soon after our trip, New Orleans' violent crime and murder rates soared (CBS Interactive, 2007).

Another resident, George, expressed his hope through wry humor. He told us that he had wanted to remodel his home before Katrina but could not because of his wife's asthma. Katrina and a FEMA trailer made the project possible, although, he said, "I hadn't planned on this much remodeling!"

\section{Community}

Many residents lamented the loss of their close-knit communities as much as or more than the loss of their possessions. A primary aspiration these residents expressed was to regain the sense of community that had been so strong before the flood. Returning residents employed several strategies to accomplish this aim.

Bernie had worked feverishly, to the point of repetitive-stress injury to both wrists, to restore his house. His goal was to provide housing to his extended family and neighbors while they worked on their own homes. Similarly, John was repairing his house not for himself, but for neighbors rebuilding their homes. John was planning an event to bring neighbors together to share rebuilding efforts and to restore relationships. Bernie said that he had come back not just to rebuild his family's home, but to be an example to his neighbors. "I want people to drive down the street for the first time and see lights on in my house," he said. "That will show them that it's possible to move home." Joy donated many of her remaining possessions to neighbors who needed them more than she did. George was proud that he and his wife had contacted every one of their immediate neighbors, even though they all had scattered after the storm. He pointed to each house in turn, telling us whether the residents planned to return. Most did intend to return. Glen also was trying to contact his neighbors to bring the community together to help one another. We saw clearly that most Ninth Ward residents knew their neighbors and cared about what was happening to them. They treated one another like extended family.

It was inspiring to find that despite the terrible destruction to the Lower Ninth Ward, residents were beginning to return and were committed to rebuilding both their infrastructure and their community. For us, it was a good reminder that, especially in times of need, relationships are paramount. As we got to know the residents, we came to understand why it was so disheartening for them to lose their community: it pre-dated Hurricane Katrina, it had sustained their daily lives, and apart from their dead, they mourned its loss more than anything else.

\section{Development of a Passion for Social Justice}

We feel that what we most accomplished during the seven days we spent in the Ninth Ward was our own personal growth as young psychologists developing a passion for social justice work. In the scholarly literature, there has been a large emphasis on working toward social justice, but it "has not resulted in much discussion about what social justice work actually looks like or what kinds of principles and struggles such work entails" (Goodman et al., 2004, p. 794). We would not be so presumptuous as to suggest that our work in the Ninth Ward increased the level of social justice for the people living there, but the principle of social justice was the 
Journal for Social Action in Counseling and Psychology

Volume 1, Number 2, Spring 2008

driving force that brought us to the Ninth Ward. As such, we can say that our project was a concrete attempt to work toward social justice.

We feel that in learning about social justice, we personally experienced in varying degrees the six components of social justice work that Goodman et al. (2004) identify, many of which have appeared throughout this article: "(a) ongoing self-examination, (b) sharing power, (c) giving voice, (d) facilitating consciousness raising, (e) building on strengths, and (f) leaving clients with the tools for social change" (p. 789). In joining CGC, we tried to bring the counseling work we do at the individual level to the larger and more systemic level by suggesting change in CGC's outreach program, and hopefully in the way they bring their services to people who need them. Vera and Speight (2003) address the need for psychologists to adjust their roles in working with diverse people, suggesting that multiculturally competent social justice work, especially in crises, should involve performing services other than therapy. These services can include outreach, helping people activate services that provide emergency aid, identifying free legal services, advocacy, prevention programs, and psychoeducational interventions.

In multiculturally competent social justice work, it is also important to be aware of one's own biases. Helms and Cook (1999) suggest that these types of biases can influence a psychologist's actions, thoughts, and feelings toward people in terms of racial dynamics and interpersonal interactions. Following this suggestion, before leaving for New Orleans, we wrote down many of our fears about working with Ninth Ward residents. Some of the more notable fears included: (a) "I am anxious about approaching and establishing connections with Ninth Ward residents because they are of a different culture/ethnicity from me and may misperceive me as the enemy (i.e. White governmental workers) or as rich," (b) "How do I deal with the guilt I experience from hearing about these residents' painful stories?," and (c) "I do not know enough about the culture of Ninth Ward residents to understand their issues in a cultural context (i.e., to be culturally sensitive)." Many of our pre-trip concerns centered on our cultural and privilege-based differences from Ninth Ward residents.

Though in some ways these differences may have hampered our work, we believe that together they were actually one of our greatest assets. Many African-American residents of the Ninth Ward had come together to support each other, so they already knew that people similar to themselves were supportive of them. Yet, we sensed a frustration in many residents toward the government and toward people who did not understand the adversities that residents were facing. Because we were different in many ways, we wanted directly to show residents that people of different backgrounds and ethnicities cared about what they were experiencing. In an interview in April 2006, CGC founder Melik Rahim said about CGC's spring-break volunteers:

[Common Ground Collective] has done what the city refused to do, and I'm not talking about the work. I'm talking about bringing people together. For the first time in the history of this city, you see Whites in the Ninth Ward, in the Lower Ninth Ward, working side by side, and in many cases working in the homes of Blacks, trying to help them get their lives back in order. Just think what that's doing to undo the racism that exists here... Now you're starting to see individuals come in and breaking these edifices that we've built to separate ourselves. And this has done [tremendous good] for race relations; it's offered hope. (Interview with Melik Rahim, 2006) 
Journal for Social Action in Counseling and Psychology

Volume 1, Number 2, Spring 2008

Of course, our relief project probably did very little in an ultimate sense of achieving the aims that Melik Rahim was advocating, but chipping away at the wall of racism, especially our own, was one of the central aims of our project.

\section{Suggestions for Counselors, Psychologists, and Graduate Students in Disaster Relief}

Before we left, the volunteer coordinator of CGC asked us to create guidelines for future outreach work in the Ninth Ward. These guidelines were based on the pre-trip training we had received, the National Organization of Victim Assistance (NOVA) model of crisis intervention (Young, 1989; Young \& Stein, 1983) from which we had worked closely, and our personal experiences doing outreach. The following eight suggestions are an extension of the CGC guidelines we created and are intended to help counselors, psychologists, and graduate students make initial outreach contacts with people affected by disasters or other mass crises:

(a) Perform community outreach for an organization that provides tangible aid to people in crisis. By incorporating ourselves within CGC, we were able to approach residents directly with food, water, and pamphlets that provided directions for accessing tangible aid, such as house gutting, FEMA assistance, food distribution, tool lending, and emergency housing.

(b) Gather information about available resources to assist people in meeting their immediate practical needs. This is based on the NOVA technique "prediction and preparation," which involves providing resource information. In this role, volunteers must know about local and governmental resources, physical and mental health services, financial assistance, supply distribution, temporary housing, and community support (Farberow \& Frederick, 1978).

(c) Refer to yourself as a "volunteer" within the organization, not as a "psychologist" or another stigmatized professional title. Overall, outreach volunteers should attempt to make residents feel as comfortable as possible by approaching them on a personal-as opposed to professional-level with humility and genuineness (American Red Cross, 1982).

(d) Offer to help the person in crisis with manual jobs such as cleaning, house repair, or yard work. This is what DeWolfe (1992) refers to as the "over-a-cup-of-coffee" informal intervention, which often provides segue into empathetic dialogue.

(e) Allow the person in crisis to tell her or his story, and then validate it. This is based on the NOVA technique "ventilation and validation," which involves using active listening to assure the person in crisis that her or his reactions are normal, while at the same time honoring the individual's unique experiences.

(f) Prepare people for trauma reactions that might develop over time. If you have experience with this realm of professional work, you can describe in basic terms some typical trauma reactions, such as post-traumatic stress. Also, empathetic dialogue and educational outreach may actually improve residents' coping abilities and curtail maladaptive trauma reactions before their onset (Erikson, 1976). 
Journal for Social Action in Counseling and Psychology

Volume 1, Number 2, Spring 2008

(g) Do not put yourself in a situation beyond your level of expertise. The American Psychological Association (2006) asks the question: "Should graduate students, predoctoral interns, and postdoctoral fellows be allowed to participate in volunteer services before obtaining their licenses to practice psychology?" (p. 520). The answer depends on what type of work the volunteer is doing. It is our firm conviction that untrained graduate students and inexperienced counselors or psychologists should not perform psychotherapy with people affected by disasters. Instead, volunteering can include work like that mentioned above and suggested by Vera and Speight (2003).

(h) Be wary of forming potentially harmful short-term therapeutic relationships. Even trained counselors and psychologists should be careful of performing psychotherapy with residents because a one-time therapy session may unlock psychological issues that cannot properly be addressed.

\section{Conclusion}

During our seven days in the Ninth Ward, we had the opportunity to speak with dozens of residents. Though we at times felt helpless, guilty, privileged, sad, and happy, we tried our best to show residents that we truly cared about how they were doing. People such as Bernie, who walked us through every step of his escape from the flood, and Deborah and Emma, who allowed us to help them cut weeds, probably affected us much more than we affected them. As we learned more deeply to value our cultural and ethnic differences, as well as their implications in working with diverse populations, we began to develop a sensitivity that we believe will profoundly affect our research and clinical careers. Specifically, we will directly apply the passion ignited on this project to work with underserved populations, to serve as public allies for them, and to provide them with mental health resources too often reserved for people who can more easily afford them. Every member of our group is involved in research on either multicultural sensitivity in health care, ethnic-group differences, social justice, or a combination of these areas. Thus, the economic and ethnic differences we observed relative to accessing resources and coping with disasters will be a platform for our future research and clinical work. Overall, working with Ninth Ward residents profoundly affected each of our lives and helped fuel the passions driving our career and personal aspirations.

\section{References}

American Psychological Association. (2006). APA's response to international and national disasters and crises: Addressing diverse needs. American Psychologist, 61, 513-521.

American Red Cross. (1982). Providing Red Cross Disaster Health Services (ARC 3076-A).

Associated Press. (2006). Nagin: Katrina aid slowed by racism. Retrieved October 20, 2007, from http://www.cbsnews.com/stories/2006/08/18/national/main1913712.shtml.

CBS Interactive. (2007). Big Easy homicides soar. Retrieved October 18, 2007, from http://www.cbsnews.com/stories/2007/01/11/eveningnews/main2352929.shtml.

DeWolfe, D. (1992). A guide to door-to-door outreach. In Final Report: Regular Services Grant, Western Washington Floods. State of Washington Mental Health Division. 
Journal for Social Action in Counseling and Psychology

Volume 1, Number 2, Spring 2008

Erikson, K. T. (1976). Loss of communality at Buffalo Creek. American Journal of Psychiatry, $133,302-305$.

Farberow, N. L., \& Frederick, C. J. (1978). Training manual for human service workers in major disasters. Rockville, Maryland: National Institute of Mental Health.

Get on the bus. (2006). Retrieved September, 12, 2006, from http://www.commongroundrelief. org/node/55

Greater New Orleans Community Data Center (2007). Lower Ninth Ward neighborhood: People \& household characteristics. Retrieved October 20, 2007, from http://www.gnocdc.org/orleans/8/22/people.html.

Goodman, L. A., Liang, B., Helms, J. E., Latta, R. E., Sparks, E., \& Weintraub, S. R. (2004). Training counseling psychologists as social justice agents: Feminist and multicultural principles in action. The Counseling Psychologist, 32, 793-837.

Helms, J. E., \& Cook, D. A. (1999). Using race and culture in counseling and psychotherapy: Theory and process. Boston: Allyn \& Bacon.

Interview with Melik Rahim, Common Ground Relief. (2006). Retrieved September, 12, 2006, from http://www.radio4all.net/proginfo.php?id=17551

National Center for Missing and Exploited Children. (2006). Katrina/Rita missing persons hotline: Update on calls/cases. Retrieved September 1, 2006, from http://www.

missingkids.com/en_US/documents/KatrinaHotlineUpdate.pdf

Philbin, W. (2006). NOPD: City is safer after storm. The Times-Picayune. Retrieved on September 1, 2006, from http://www.nola.com

Pole, N., Best, S. R., Metzler, T., \& Marmer, C. (2005). Why are Hispanics at greater risk for PTSD? Cultural Diversity and Ethnic Minority Psychology, 11, 144-161.

Rappaport, J. (2000). Community narratives: Tales of terror and joy. American Journal of Community Psychology, 28(1), 1-24.

Richmond, N. (1993). After the flood. American Journal of Public Health, 83, 1522-1524.

Warner, C., \& Scott, R. T. (2005). Where they died. The Times-Picayune. Retrieved on September 2, 2006, from http://www.nola.com

U.S. Census Bureau. (2000). The United States census 2000. Retrieved on September 12, 2006, from http://www.census.gov/po/www/foia/foiaweb.htm

U.S. Census Bureau. (2004). The United States census 2004. Retrieved on September 12, 2006, from http://www.census.gov/po/www/foia/foiaweb.htm 
Journal for Social Action in Counseling and Psychology

Volume 1, Number 2, Spring 2008

Vera, E. M., \& Speight, S. L. (2003). Multicultural competence, social justice, and counseling psychology: Expanding our roles. The Counseling Psychologist, 31, 253-272.

Young, M. A. (1989). Crime, violence, and terrorism. In R. Gist \& B. Lubin (Eds.), Psychological Aspects of Disasters. New York: Wiley \& Son.

Young, M. A. \& Stein, J. H. (1983). The Victim Service System: A Guide to Action. Washington, D.C.: National Organization for Victim Assistance. 